\title{
WORKSHOP PENYUSUNAN PERANGKAT PEMBELAJARAN BAHASA INGGRIS BAGI INSTRUKTUR LEMBAGA KURSUS NON FORMAL
}

\author{
Nita Sari Narulita Dewi, Yusup Supriyono, Ruslan \\ Universitas Siliwangi \\ nitasarinarulitadewi@unsil.ac.id, yusupsupriyono@unsil.ac.id, ruslan@unsil.ac.id
}

\begin{abstract}
The purpose of the workshop program for the preparation of English learning devices is to help solving the problems faced by English language courses, English Camp Cipta Guna in Cihaurbeuti-Ciamis and PKBM Gema in Tawang-Tasikmalaya, namely, the instructor's low ability to develop syllabus and to develop interesting and effective teaching materials, besides pedagogic abilities. The workshop method was chosen as the right solution in solving the problem. Participants took part in activities that include syllabus preparation activities, development of teaching materials, and micro teaching. 15 instructors from two English language courses participated in the workshop and they were directly and actively involved starting from the planning, implementation and evaluation stages. The achievements of this program are the increased knowledge and abilities of participants in the preparation of syllabus as evidenced by the quality of the syllabus in accordance with the needs and abilities of the students; the participant can independently make interesting teaching material that is in accordance with the competencies set out in the syllabus; Participants' pedagogic abilities are better as evidenced by their better understanding in the principle of second language teaching, teaching methods or techniques. The results of this program are also expected to inspire similar institutions and contribute to the development of English teaching practices that use the English language immersion method
\end{abstract}

Keywords: Instructional tool, English, workshop, Non-Formal

\begin{abstract}
Abstrak
Tujuan dari program workshop penyusunan perangkat pembelajaran bahasa Inggris ini adalah membantu memecahkan masalah yang dihadapi oleh lembaga kursus bahasa Inggris Non formal, English Camp Cipta Guna di Cihaurbeuti-Ciamis dan PKBM Gema di Tawang-Tasikmalaya yaitu, rendahnya kemampuan instruktur dalam menyusun silabus dan mengembangkan bahan ajar yang menarik dan efektif, disamping kemampuan pedagogic. Metode workshop dipilih sebagai solusi tepat dalam memecahkan masalah tersebut. Peserta mengikuti kegiatan yang mencakup kegiatan penyusunan silabus, pengembangan materi ajar, dan micro teaching. 15 instruktur yang berasal dari dua lembaga kursus bahasa Inggris mengikuti kegiatan workshop dan mereka terlibat secara langsung dan aktif mulai dari tahapan perencanaan, pelaksanaan dan evaluasi. Capaian dari program ini adalah meningkatnya pengetahuan dan kemampuan peserta dalam penyusunan silabus yang dibuktikan dengan kualitas silabus yang sesuai dengan kebutuhan dan kemampuan peserta didik; peserta secara mandiri dapat membuat materi ajar yang menarik yang sesuai dengan kompetensi yang telah ditetapkan dalam silabus; kemampuan pedagogic peserta lebih baik yang dibuktikan dengan pemahaman mereka yang lebih baik dalam prinsip pengajaran bahasa kedua, metode atau teknik pengajaran dan penilaian. Hasil dari program ini diharapkan pula dapat menginspirasi lembaga sejenis dan memberikan kontribusi terhadappengembangan praktek-praktek pengajaran bahasa Inggris yang menggunakan metode English language immersion.
\end{abstract}

Kata Kunci: Perangkat pembelajaran, bahasa Inggris, workshop, Non Formal 


\section{PENDAHULUAN}

Analisa situasi dilakukan dengan melakukan identifikasi pada beberapa fokus permasalahan yang dimiliki lembaga English Camp Cipta Guna (ECCG) dan PKBM GEMA seperti, manajemen, sumber daya, instruktur, bahan pustaka, fasilitas, dan lingkungan belajar sekitar lembaga hingga dilakukan pembatasan masalah yang urgen sekali untuk dipecahkan, yaitu lemahnya kemampuan para instruktur dalam penyusunan syllabus dan pengembangan bahan ajar. Disamping itu, rendahnya kemampuan para instruktur melaksanakan pengajaran yang berkualitas masih menjadi masalah yang dihadapi pada lembaga ini.

Secara terperinci dapat dideskripsikan sebagai berikut: Pertama, rendahnya kemampuan instruktur dalam menyusun syllabus menyebabkan kompetensi yang dirumuskan dengan kebutuhan peserta didik belum memperlihatkan hubungan yang kuat. Padahal silabus merupakan kumpulan kompetensi pada level tertentu yang harus dicapai melalui proses pembelajaran. Demikian syllabus tidak hanya sekedar synthetic silabus yang menyediakan informasi specific course yang akan dicapai oleh siswa (Ur, 2012:186) namun silabus merupakan proses yang menggambarkan bagaimana siswa belajar dan bagaimana guru dalam melakukan pengajaran (Richards, 2013) yang seyogyanya didalam penyusunannya dilakukan negosiasi atau memperhatikan kebutuhan dan kemampuan peserta didik. Kedua, bahan ajar yang berkualitas masih jauh dari standar sehingga materi ajar kurang memberikan pengalaman belajar yang tinggi bagi peserta didik. Padahal materi dapat memberikan gambaran bagi peserta didik mengenai bahasa sasaran yang akan dipelajari dan memfasilitasi mereka pengalaman-pengalaman belajar bagaimana bahasa tersebut digunakan (Tomlinson, 2012) dan materi ajar harus mampu meningkatkan kemandirian siswa dalam belajar. Disamping itu materi harus menunjukan tingkat proficiency tertentu sesuai dengan kemampuan dan kebutuhan peserta didik. Oleh karena itu, materi harus memiliki prinsip authenticity, yang mampu memotivasi dan meningkatkan minat dan memfasilitasi siswa menggunakan bahasa yang nyata yang dapat mereka temukan dalam kehidupan sehari-hari. Disamping itu authentic materials dapat mendorong mereka mencapai sukses dalam belajar ketika mereka menggunakan bahasa yang dibutuhkan dalam kehidupannya (AlAzri and Al-Rashdi, 2014). Ketiga, rendahnya kemampuan pedagogik instruktur menyebabkan proses pembelajaran kurang menarik dan efektif. Padahal pengetahuan methodology ini sangat penting dan menentukan bagaimana syllabus yang telah disusun dapat diaktualisasikan dalam proses pembelajaran. Seperti yang diungkapkan oleh DarlingHammond and McLaughlin (2011) bahwa kemampuan pedagogik guru akan mampu menciptakan suasana pembelajaran yang aktif, kolaboratif 
dan reflektif yang dapat berguna bagi siswa dalam kegiatan belajarnya.

Workshop penyusunan perangkat pembelajaran bahasa Inggris bagi para instruktur lembaga Kursus Non Formal menjadi solusi yang diusulkan pada program ini, dengan memperhatikan berbagai hal sehingga program ini layak dilaksanakan, diantaranya, Kebijakan lembaga. Kebijakan lembaga sangat mendukung program ini dengan dibuktikan lembaga bersedia mengorganisasikan peserta didik dan intruktur untuk terselenggaranya program ini.Para instruktur diwajibkan oleh lembaga untuk mengikuti program dan diperolehnya perizinan menggunakan fasilitas teknologi dan ruang kelas untuk kegiatan.

a. Fasilitas ruang kelas/lab/camp

Fasilitas yang dimiliki lembaga dapat digunakan untuk proses pembelajaran secara maksimal, baik fasilitas yang secara langsung menunjang proses pembelajaran, seperti ruang kelas, media, internet, computer dan fasilitas yang tidak secara langsung berkaitan dengan proses pembelajaran.

b. Kesediaan para instruktur bahasa Inggris

Para instruktur yang bersedia menjadi bagian dari program sebagai peserta workshop menjadi faktor utama terhadap suksesnya program akan dilaksanakan.

c. Lingkungan belajar

Lingkungan belajar yang kondusif menjadi faktor pendukung lainnya sehingga program ini dapat dilaksanakan, diantaranya fasilitas camp yang dilengkapi free internet access yang bisa diberikan kepada peserta maupun pelatih.

Berdasarkan analisa situasi di atas dan hasil keputusan bersama lembaga ECCG dan PKBM GEMA, maka telah ditetapkan beberapa permasalahan prioritas yang dihadapi oleh lembaga mitra yang membutuhkan penanganan yang maksimal, yaitu sebagai berikut:

a. Rendahnya kemampuan instruktur ECCG dalam menyusun silabus yang sesuai dengan kebutuhan dan kemampuan peserta didik,

b. Rendahnya kemampuan instruktur dalam mengembangkan materi pembelajaran yang menarik

c. Rendahnya kemampuan instruktur dalam pedagogic sehingga berpengaruh pada kualitas proses pembelajaran.

Workshop penyusunan perangkat pembelajaran bahasa Inggris bagi para instruktur ini akan mengupayakan beberapa solusi pemecahan masalah sesuai dengan prioritas masalah seperti yang disebutkan diatas, yaitu sebagai berikut:

a. Kemampuan penyusunan silabus para instruktur yang masih rendah dapat dipecahkan melalui pelatihan penyusunan berbagai jenis silabus, seperti structural syllabus, lexical syllabus, situational and topic-based syllabus, functional-notional syllabus, standard-based syllabus, dan mixed syllabus (Ur, 2012:186). Jenis jenis silabus ini diberikan agar instruktur dapat menyusun silabus sesuai kebutuhan peserta dan 
memahami prinsip penyusunan silabus yang baik.

b. Kemampuan pengembangan bahan ajar para instruktur yang masih rendah dapat dipecahkan melalui pelatihan pengembangan materi ajar yang gayut dengan silabus yang telah dibuatkan, dengan memperhatikan prinsip prinsip penyusunan materi ajar dari Tomlinson dan Harwood, (2010), sehingga para instruktur dapat mengembangkan materi ajar sendiri sesuai kebutuhan. Authentic materials dan technological-based materials juga diberikan untuk membuat materi ajar yang lengkap dan menarik. Melalui teknik-teknik penyusunan materi ajar seperti adopsi, adaptasi, dan kreasi.

c. Kemampuan pedagogic para instruktur yang masih rendah dapat dipecahkan melalui kegiatan micro teaching, yang mana intruktur terlebih dahulu menyusun silabus, mengembangkan materi ajar dan mampu menampilkan pembelajaran dengan baik menggunakan silabus dan materi ajar yang telah dibuat sebelumnya. Selain itu peserta diberikan pembekalan mengenai classroom management yang dapat mengontrol dan memecahkan masalah perilaku siswa dikelas
(Dibapile, 2102) dan dapat membantu guru dalam membangun lingkungan belajar yang menunjang akademik dan sosial emosional belajar siswa (Evertson and Weinstein, 2006 dalam Korpershoek, et al., 2014). Dengan kata lain kualitas kelas dapat dipengaruhi seberapa cerdas guru mengelola kelas (Wright dalam Anne Burns and Richard, 2012)

Diharapkan workshop Penyusunan perangkat pembelajaran ini dapat bernilai secara ekonomis, praktis, efektif, dan terukur dan tentunya menjadi solusi alternatif dalam memecahkan masalah yang dihadapi Lembaga English Camp Cipta Guna (ECCG) dan PKBM GEMA dan dapat meningkatkan layanan pendidikan bahasa Inggris yang lebih berkualitas.

\section{METODE PELAKSANAAN}

Berdasarkan skala prioritas permasalahan yang telah ditetapkan secara bersama dengan lembaga, maka Prosedur kerja dalam pelaksanaan kegiatan Workshop Penyusunan perangkat pembelajaran bahasa Inggris bagi instruktur ini dapat dilihat dari gambar berikut ini: 


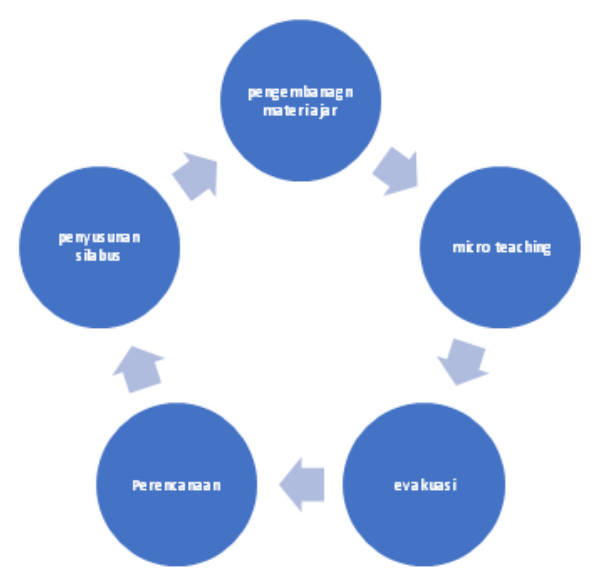

Gambar 1. Prosedur Workshop

Pertama, perencanaan dimaksudkan sebagai kegiatan awal untuk memperoleh data awal tentang kelebihan dan kekurang peserta, serta pula rencana kerja yang akan dilakukan selama workshop berlangsung. Hal lain seperti jadwal, tata tertib, dst. dikomunikasikan juga kepada peserta

Kedua, Penyusunan silabus, dilakukan dengan memberikan pemhaman kepada peserta prinsip dalam penyusunan silabus dan jenisjenis silabus dalam pengajaran bahasa, khususnya bahasa Inggris.

Ketiga, pengembangan materi ajar dan media pembelajaran dilakukan oleh peserta secara mandiri dengan dibimbing oleh pelatih. Peserta mengembangkan materi ajar menggunakan teknik adopsi, adaptasi, dan kreasi. Authentic material baik menggunakan media teknologi dan cetak diberikan agar materi ajar yang dikembangkan menarik.

Keempat, micro teaching dilakukan oleh peserta mengunakan silabus yang merka susun dan materi ajar yang mereka kembangkan. Sementara itu peer teaching dilakukan agar para peserta saling memberikan masukan atau koreksi demi pengembangan kemampuan mengajar yang lebih baik.

Kelima, evaluasi berjalan dilakukan bersama antara peserta dengan pelatih untuk menggali data tentang kelebihan dan kekurangan program workshop yang sedang dilakukan dan dicari penyelesaian masalahnya untuk selanjutnya dilakukan perbaikan dan penyempurnaan kegiatan.

Lembaga mitra berpartisipasi dalam penyediaan peserta pelatihan dan perizinan penggunaan fasilitas pembelajaran untuk kepentingan workshop misalnya ruang kelas, Komputer dan lain-lain.

Evaluasi program yang dilakukan menjadi bahan informasi sehingga bisa ditarik kesimpulan mengenai program yang telah dilaksanakan, sehingga bisa diketahui kelebihan dan kekurangan program dan kemampuan akhir peserta pelatihan setelah mengikuti kegiatan. Sebagai tindak lanjut dari program ini, para peserta yang telah selesai mengikuti workshop akan menjadi 
mentor kegiatan serupa dengan jumlah peserta yang lebih besar dengan cara menjalin kerjasama yang lebih luas lagi dengan lembaga-lembaga sejenis dan pemerintah setempat. Selanjutnya membentuk lembaga assosiasi Instruktur lembaga kursus non formal dibidang bahasa Inggris sebagai wadah pengembangan dan pelatihan kemampuan bahasa Inggris yang dimotori para instruktur dari kedua lembaga yang telah dilatih.

\section{HASIL DAN PEMBAHASAN}

Sesuai permasalahan yang dihadapi oleh lembaga lembaga non formal tersebut, maka setelah dilakukan kegiatan wokshop, diperoleh data sebagai berikut:

a. Silabus

Setelah mengikuti workshop, para peserta workshop mengalami peningkatan pengetahuannya dan kemampuannya dalam menyusun silabus yang sesuai dengan kebutuhan dan kemampuan peserta. Hal ini dibuktikan dengan silabus yang secara integrative memasukan semua komponen bahasa dan skill kedalam satu program. Sehingga didalamnya mencakup pengajaran kosa kata dan pronunciation, grammar, listeningspeaking (public speaking: speech, talk show, telling stories, etc.), writing dan reading.

Syllabus yang dikembangkan mencakup materi-materi berikut ini:

\section{A. Vocabulary and Pronunciation}

- word pronunciation and spelling

- word category

- vocabulary building

- words and sentences making
Techniques: twister tongue, drill, guessing game, giving clues, mime, TPR, telling stories with dramatization, listen and do, listen and draw.

Media: online dictionary, pictures, film, photos, stories book, webs, cards.

\section{B. Grammar and Structure}

1. uses of to be (is, am, are, was, were) and to do (do, does, and did)

2. uses of Wh-Questions + How

3. parts of speech (noun, verb ,pronoun, adverb, adjective, article, conjunction, preposition, interjection

4. tenses (present, past, future,)

5. modals (will, may, shall, have to, has to, should, must, might, need to)

Techniques: guessing game, interview, (questioning-answering), role play, mime, whispering

Media: webs, photos, pictures, realia (e.g handphone, bag, etc), student's idols, stories, environment, stories, student's own, Youtube

\section{Listening and speaking}

\section{Interpersonal conversation}

- making appointment

- self-introduction and introducing others, and leave taking

- small talk and chit-chat

- giving compliments, thanking, and apologizing

- asking for permission, making a request and giving instruction

- daily activities

- telling about planning

- description of persons, things and places

- making and operating something 
- exploration of information about popular places, things and persons

- making agreement and disagreement

\section{Transactional conversation}

- asking identities

- asking and giving opinion

- asking for, giving, and offering a help and ordering something

- asking and giving direction

- asking for reservation

- asking and refusing invitation

- asking prices

\section{Telling stories}

- recounting self-experiences

- retelling and responding to news, speech, and stories

- telling stories (fiction and nonfiction)

Techniques; role play, game, interview, monolog (storytelling), drama

Media: paper, video, student's own, stories, films

\section{Writing}

- writing a photo voice/caption

- writing memo to a friend, and a family

- writing an announcement

- writing advertisements (product, service, and event)

- writing business letters

- apology letters

- appreciation and congratulation letters

- argumentative and persuasive writings

- writing literary works

- descriptive writing for English journalism)

- interview for English journalism
- making a news report for English journalism

Techniques: Storytelling, chain story, questioning and answering, drama, dramatization, making notes, interview, survey

Media: Paper, stories, student's own, video, Youtube

\section{E. Reading}

- reading with correct pronunciation

- reading functional text (advertisements, announcements, memos, and letters

- reading news

- reading stories

- reading comprehension on fiction and nonfiction texts

Techniques: skimming, scanning, shared reading Media: story books, text, news text, newspaper, magazines, comics

b. Materi Ajar

Peserta secara mandiri dapat membuat materi ajar yang menarik yang sesuai dengan kompetensi yang telah ditetapkan dalam silabus. Materi yang disusun cukup sudah cukup menggambarkan upaya-upaya melatih kemandirian siswa dan menunjukan tingkat proficiency bahasa Inggris melalui penyusunan bahan ajar yang otentik (authentic materials). Hal ini sesuai dengan temuan penelitian yang dilakukan oleh Mohd Deni and Zainal (2014) Bahwa authentic material dapat meningkatkan kualitas pembelajaran dalam berbagai cara dan mampu membangun critical thinking siswa. Oleh karena itu keterlibatan penggunaan teknologi internet menjadi sangat penting dalam melakukan seleksi bahan ajar yang gayut dengan silabus yang 
telah didesain sebelumnya. Sebagai contoh dapat dilihat sebagai berikut:

A. Pengajaran kosa kata dan spelling

1. Purpose: peningkatan pemahaman kosa kata dan pelafalan, writing reading, listening and speaking yang secara terintegrasi dalam satu pertemuan

2. Techniques: drill, tongue twister, discussion

3. Source: http://www.myenglishpages.com/sit e_php_files/vocabulary-exerciseaffixes.php)

4. Time allocation: 3 jam ( @60 menit)

5. Materials:

I. Use a prefixes to find the opposite of these verbs:

\begin{tabular}{|l|l|}
\hline 1- Wrap & \\
\hline 2- Use & \\
\hline 3- Agree & \\
\hline 4- Engage & \\
\hline 5- Behave & \\
\hline 6- Understand & \\
\hline 7- Fold & \\
\hline 8- Spell & \\
\hline 9- Connect & \\
\hline
\end{tabular}

II. Put the words in brackets in the appropriate form (use a prefixes or a suffixes):

1. He was acting in a very way. (child)

2. She looked .She started to cry. (happy)

3. $\mathrm{He}$ passed his exam. $\mathrm{He}$ was__ for the second time. (succeed)

4. The team that he supported was able to win the (champion)
5. I couldn't find any in his theory. (weak)

6. He wants to be a when he grows up. (mathematics)

7. There were only a of people at the match. (hand)

8. The road was too narrow, so they had to it. (wide)

9. I think that you should your decision. It may not be the best thing to do. (consider)

10. You need a __ of motivation, organization and hard work to realize your dreams.(combine)

III. Look at the pictures and write your sentences

1. Look at the picture, how many apples do you see on the table? And what is the man doing in the kitchen?

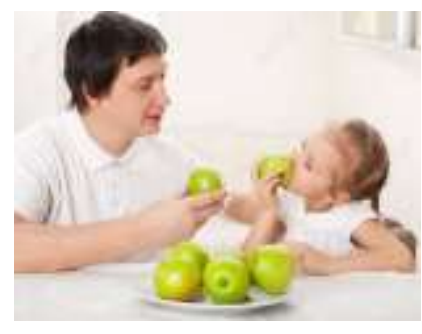

2. Using the given picture, make two sentences based on your opinion.

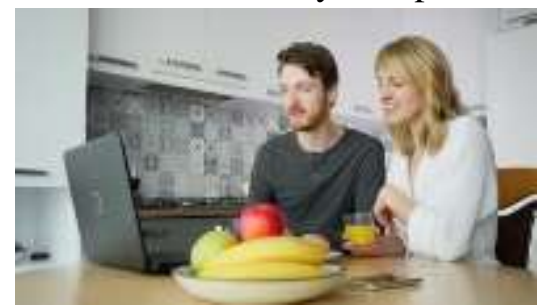


3. Using the given picture, what makes the man help the homeless?

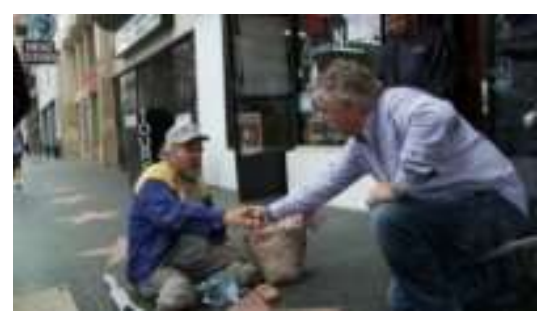

4. What makes the two pictures different?
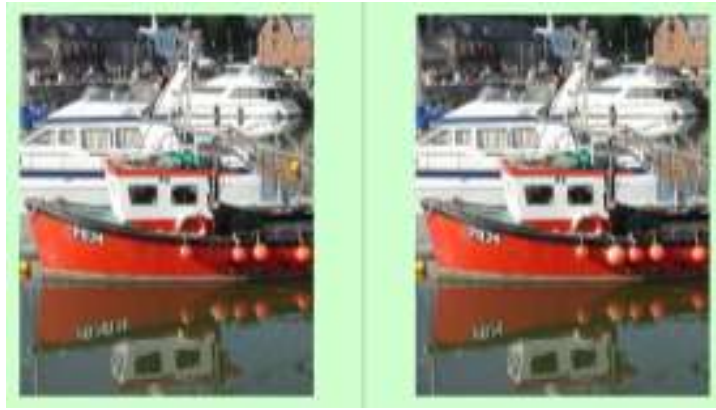

5. Using the given comic strip, fill the missing dialog to make complete dialog

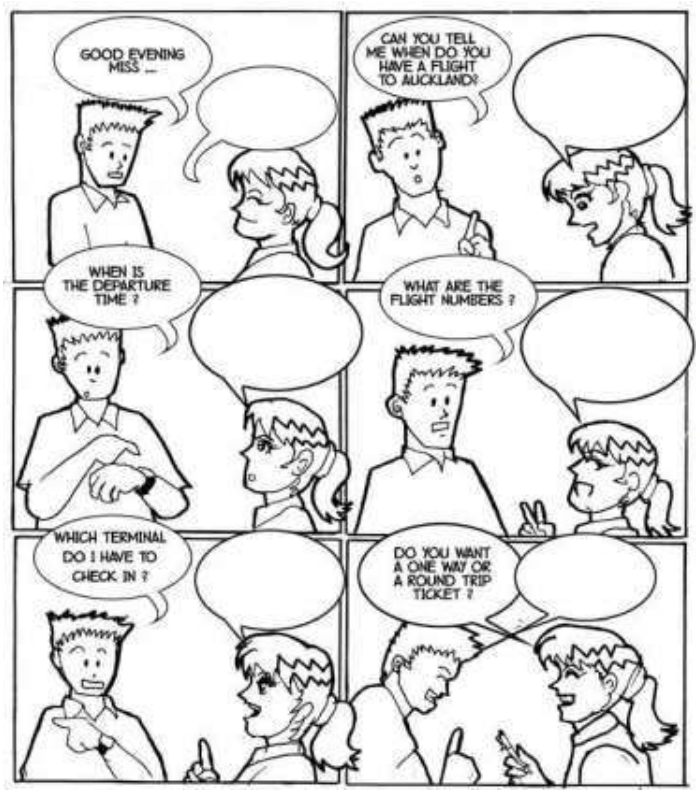

6. Using the given picture, tell a story using your own words.

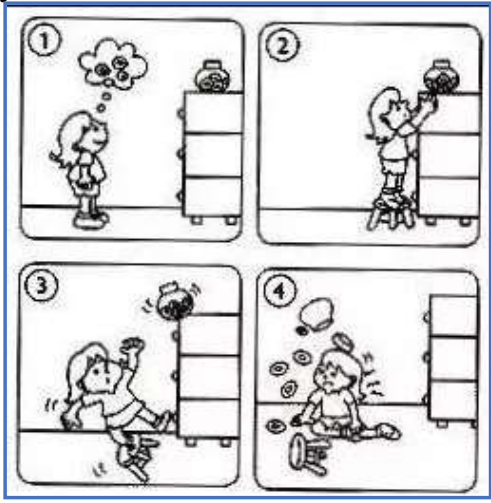

\section{Kemampuan Pedagogik}

Workshop in action atau workshop yang terintegrasi dengan praktek secara langsung memungkinkan peserta belajar teori dan praktek. Dan menggunaan prinsip belajar learning by doing melalui micro teaching, mereka mampu mengimplementasikan metode atau teknik pengajaran dengan lebih baik dan setelah itu mereka mengevaluasi secara bersama. Mereka secara aktif melakukan simulasi dalam pengajaran telling stories, talkshow, pidato, dll. Kemampuan classroom management mereka mengalami peningkatan juga, diantaranya kemampaun membagi kelas, sitting arrangement, volume suara, membangun percaya diri dan tanggung jawab, dan hubungan emosional yang kuat antara guru dan peserta didik. 


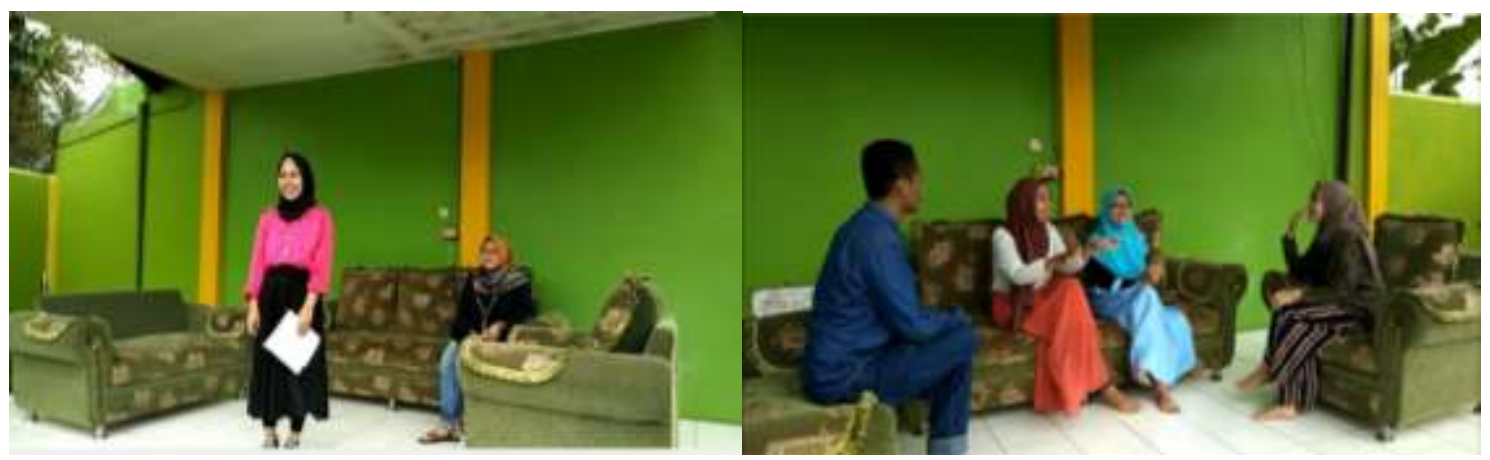

Gambar 2. Melatih teknik monolog dan dialog

\section{PENUTUP}

Berdasarkan hasil yang diperoleh dapat disimpulkan bahwa kegiatan workshop penyusunan perangkat pembelajaran bahasa Inggris ini memberikan efek positif bagi peserta pelatihan, hal ini dapat dilihat dari kemampuan pedagogik yang semakin baik, kemampuan menyusun bahan ajar yang lebih baik, dan membuat silabus yang sesuai dengan kebutuhan dan kemampuan peserta didik. Kemampuan mereka yang meningkat dapat menumbuhkan rasa percaya diri yang tinggi terhadap penciptaan pembelajaran yang efektif, sehingga peserta didik dapat menguasai pembelajaran bahasa Inggris dengan lebih baik.

Metode immersion yang dilakukan pada kegiatan workshop telah mampu meningkatkan kemampuan para instruktur, baik dari segi administrasi maupun keterampilan berbahasa.

Kemampuan menyusun silabus, materi ajar dan mengajar bahasa Inggris secara efektif membutuhkan komitmen yang tinggi, sehingga para intruktur disarankan sebagai berikut:

a. Melakukan penelitian reflective teaching untuk melihat kelebihan dan kekurangan dalam pengajaran

b. Berupaya terus berinovasi dalam melakukan pengajaran bahasa Inggris melalui pengembangan silabus, materi ajar, metode pengajaran mutakhir,

c. Meningkatkan rasa percaya diri dengan cara meningkatkan kemampuan bahasa Inggris (English Proficiency)

\section{DAFTAR PUSTAKA}

Al-Azri and Al-Rashdi. 2014. The Effect of Using Authentic Materials In Teaching International, Journal of scientific and technology research, 3 (10), 249-254.

Brown. 2007. Prinsip Pembelajaran dan Pengajaran Bahasa. Terjemahan oleh Noor Cholis dan Yusi Avianto Pareanom. Pearson Education, Inc.

Darling-Hammond, L., \& McLaughlin, M. W. 2011. Policies that support professional development in an era of reform. Kappan, 92(6), 8192.

Deni, M. and Zainal. 2014. Authentic materials for the language classroom: digitized texts via email attachments. The English Teacher, 38, $111-121$.

Dibapile, W.T.S. 2012. A Review Of Literature On Teacher Efficacy And Classroom Management. Journal of College Teaching \& 
Learning - Second Quarter 2012

Volume 9, Number 2, 79-92.

Harwood, N. 2010. English Language TeachingMaterials. Cambridge University Press: New York.

Korpershoek, et al. 2014. Effective Classroom management stratregis and Classroom management Programs for educational practice, Groningen, Belanda: Gion Publisher.

Richards, J.C. 2013. Curriculum Approaches in Language Teaching: Forward, Central, and Backward Design RELC Journal, 44(1) 5-33.

Sudarman. 2018. Peningkatan Profesionalisme Tenaga Pengajar
Sebagai Kontribusi Peningkatan MutuPembelajaran. (source: https: //www.researchgate.net/publicatio $\mathrm{n} / 324104321$ ).

Tomlinson, B. 2012. Materials development for language learning and teaching, Language . Teaching, 45.(2) 143-179.

Ur, P. 2012. English Language Teaching. Cambridge University Press: United Kingdom.

Wright, T. 2012. Managing the Classroom. In Burns and Richards (Eds.), Pedagogy in Practice in Second Language Teaching (pp. 60-67) USA: Cambridge University Press. 